\title{
Exploring the Causal Relationships of KPIs in after Sales Service Systems
}

\author{
Elena Legnani and Sergio Cavalieri \\ CELS - Research Center on Logistics and After-Sales Service \\ University of Bergamo, Department of Industrial Engineering \\ Viale Marconi, 5 - 24044 Dalmine, Italy \\ (elena.legnani, sergio.cavalieri)@unibg.it
}

\begin{abstract}
A plethora of research and industrial contributions emphasizes the economic and strategic role of services in adding further value to a product throughout its lifelong journey with the customer. However, there is still a limited comprehension of the dynamics underlying After-Sales (AS) processes along the whole service network - which usually encompasses a manufacturer, spare parts wholesalers/retailers and technical assistance centres - till the final user. AS can be no more considered as a mere corporate function, but rather as a series of interconnected activities involving more independent organizations, each one having different objectives and perspectives to be properly aligned. Starting from previous contributions of the same authors on this research topic, aim of the paper is to examine AS as a complex system of interlinked processes, to elaborate a proposal of the main Key Performance Indicators (KPIs) which can take into account the various perspectives of the different actors involved, and, as a main result, to explore the most relevant causal relationships among these KPIs.
\end{abstract}

Keywords: After-Sales Service System, Product-Services, Performance Measurement System, Systems Thinking, System Dynamics.

\section{Introduction}

Given the high market pressure, the increased competition in several industries and the reduced margins on undifferentiated products, the search for new business opportunity is emphasizing the strategic and economic role of service activities as powerful add-ons to the mere delivery of a manufactured product. The provision of services can be both an effective commercial tool during the transactional phase of product sale and a means of enduring a durable relation with the customer. In the long term, this strategy can ensure to a manufacturer and its service network stable and long-lasting cash flows and empower the degree of retention and loyalty of the client. However, despite the potential advantages, this transition from a pure manufacturer to a productservice provider is not immediate and, if not properly managed, it could have some negative side-effects [10], [18].

Provision of services require the adoption of specific forms of organizational principles, structures and processes, which could constitute a major managerial challenge for a manufacturer [9]. In addition, what is usually neglected in the industrial practice 
is the involvement of the whole downstream service network which acts as the real front-end with the final user. As a service manager of an important multinational company operating in the consumer electronics industry stated, "we do not have any direct interaction with our customers, since when they need to buy our products they go to large multi-branded retailing chains; when they have specific claims, they call at our contact centres, which we have outsourced to an external partner; when they need repair or refurbishment activities they go to our technical assistance centres, which in most cases are still run in a "mom-and-pap" way". Hence, AS service cannot be considered as a mere ancillary function within a manufacturing company but it needs to be re-interpreted as a more complex system which encompasses a series of primary and supporting processes and involves independent organisations with very often conflicting objectives and behaviours. Thus it is essential to: i) be able to develop a Performance Measurement System (PMS) which incentives all the different actors and aligns their perspectives through a common set of measurable KPIs and ii) explore and understand the beneath interrelationships among these KPIs.

Regarding the scientific literature, contributions deal essentially with descriptive models which identify and depict the main elements that constitute the service system. However, they do not capture the underneath interrelations and its intrinsic dynamic nature. Moreover, the main works propose linear models which cover just local aspects related to the service management [11], [7] without providing a whole picture of the AS system and without embracing different perspectives and effects.

An appealing challenge is to define a model which highlights the causal relationships existing among some key indicators and explore the effect that they exert on the management of the main processes and on the enhancement of the overall company performance. The analysis proposed in this paper aims at emphasizing the causal-loop relationships existing within the main KPIs of the AS system, taking into account: i) the customer perspective, in terms of customer perceived value and repurchasing attitudes; ii) the service network operational results; iii) the company perspective, in terms of profitability and investment strategies.

The paper is organized as follows: $\$ 2$ explains the meaning of modelling a global system considering overall structures, patterns and feedback loops, and it gives some insights about the adopted methodologies, namely Systems Thinking and System Dynamics; $\$ 3$ reports the causal relationships among the KPIs for each of the three identified perspectives and the main literature contributions used to build, strengthen and reinforce the elements and the relations pinpointed. $\$ 4$ shows the developed model which embraces together all the three perspectives while $\$ 5$ draws some conclusions and further developments of the work.

\section{Systems Thinking and System Dynamics}

The term System is used for many purposes ranging over economic, political and ecological issues. A system consists of distinguishable elements which are linked to each other in a certain structure. The nature of the relations can be flows of material, information as well as cause and effect loops [6]. Systems are generally open as they interact with elements of the environment and are related each other through a hierarchical architecture. Moreover, every system is active and changes its status over 
time: in fact, without the recognition of time, systems would be static and not realistic. According to [16], many advocate the development of Systems Thinking as the ability to see the world as a complex system where everything is connected to everything else. It is argued that if people had a holistic worldview, they would act in consonance with the long-term best interests of the system as a whole, identify high leverage points and avoid policy resistance. An action of one element causes effects on other elements altering the state of the system and, therefore, leading to further actions to restore the balance. These interactions or feedbacks are usually the main reasons for the complex behaviour of a system.

Modelling complex structures such as AS service systems requires a powerful tool or method which helps to understand complexity, to design better operating polices and to guide change in systems: System Dynamics is a method used to represent, analyse and explain the dynamics of complex systems along the time. The main goal of System Dynamics is to understand, through the use of qualitative and quantitative models, how the system behaviour is produced and to exploit this understanding to predict the consequences over time of policy changes to the system [12]. In the field of Supply Chain Management there are several applications of System Dynamics [1], [16] report the main uses - while contributions that explore the main causal relations of KPIs are still quite few.

Referring to the specific case of this paper, Systems Thinking is adopted as the approach to foster the understanding of the logic underlying performance generation and to identify the factors that may trigger off effective changes in the AS service system. System Dynamics will be exploited in further contributions to make simulation and what-if analyses on the developed Systems Thinking logic model.

\section{AS Service Perspectives and Related Causal Relationships}

As outlined in $\S 1$, an AS service system can be depicted as powered by three actors: the customer, the manufacturing company and the service network. The strong interaction among them is the key for managing the AS activities and achieving high performance results.

The customer is the main trigger for the AS business: his/her satisfaction and, hopefully, loyalty have a significant influence on the company profitability. Moreover, his/her continuous involvement is the fundamental basis for developing new services and co-creating value.

The company has the goal of being competitive, growing and achieving loyalty from its customers through the Product-Services offered. The company does not act alone but it operates within a service network, where different actors (e.g. spare parts wholesalers, retailers and technical assistance centres) play to guarantee a reliable, responsive and flexible service to the customers.

These powerful and intense interactions generate results that the company aims at measuring through some KPIs. A PMS for analysing the main AS KPIs has been proposed by the same authors in a previous paper presented at APMS Conference 2008 [8]. After an in-depth literature review and a validation with an industrial case study, the proposed PMS provides an integrated and multi-levelled set of measures for 
the AS area. It classifies metrics considering both strategic and operational perspectives. Indicators have been arranged in a hierarchical structure according to the following construction:

- performance attributes (reliability - RL, responsiveness - RS, agility - AG, assets AM, costs - CO and growth - GR), which are groupings for metrics used to explain company strategies and to analyse and evaluate them against others with competing approaches;

- level 1 metrics, which are strategic indicators (Key Performance Indicators - KPIs) used to monitor the overall performance of the company and its service network;

- level 2 and level 3 metrics, respectively tactical and operational indicators, which serve as diagnostic measures to identify critical processes and variations in performance against the plan.

For the sake of clarity, the main level 1 metrics (KPIs) have been reported and associated to the proper performance attributes in Table 1.

Table 1. Performance attributes and associated Level 1 metrics (KPIs) for AS

\begin{tabular}{|l|c|c|c|c|c|c|}
\cline { 2 - 7 } \multicolumn{1}{c|}{} & \multicolumn{5}{c|}{ PERFORMANCE ATTRIBUTES } \\
\hline LEVEL 1 METRICS (KPIs) & RL & RS & AG & CO & AM & GR \\
\hline Perfect Assist Completion & X & & & & & \\
\hline Assist Cycle Time & & $\mathrm{X}$ & & & & \\
\hline Assist Agility & & & $\mathrm{X}$ & & & \\
\hline Assist-Warranty-Spare Parts Costs & & & & $\mathrm{X}$ & & \\
\hline Return on Assist Assets & & & & & $\mathrm{X}$ & \\
\hline Assist Operating Income & & & & & & $\mathrm{X}$ \\
\hline Customer Loyalty & & & & & & $\mathrm{X}$ \\
\hline
\end{tabular}

Goal of this section is to explore and highlight the causal relationships existing among the main AS KPIs according to the three different players' perspectives. To support the model building, a literature analysis has been reckoned to be essential: the main contributions have helped to make and reinforce the identified relations. In literature there are few contributions that deal with service and, more specifically, with AS service as an overall system. Some contributions can be found in [3], [6] and [5]. However, it turns out that most of the analyses reported regard just a portion of the entire system with a local perspective on few specific aspects.

\subsection{The Customer Perspective}

The customer perspective is the underlying rationale that derives the customer repurchasing attitude based on his/her needs and wants. Customer loyalty is the metric explored in this loop. The service management literature discusses the links between customer satisfaction, customer loyalty and profitability. This theory argues that:

- customer satisfaction is the result of a customer perception of the value received in a transaction or relationship relative to the value expected from transactions or relationships with competing vendors [19]. In accordance with [13], [7], customer value is a balance between perceived benefits and perceived costs and sacrifices. 
- loyalty behaviours, including relationship continuance and recommendation, such as positive word of mouth or advertising, result from customer belief that the amount of value received from one supplier is greater than that available from other suppliers. Loyalty, measured in the form of customer retention, creates increased profits to the company through enhanced revenues, reduced costs to acquire customers, lower customer-price sensitivity, and decreased costs to serve customers familiar with a firm service delivery system.

Other proponents who believe that customer satisfaction influences customer loyalty, which in turn affects the profitability of a company are [5], [11] and [14].

Figure 1 shows the main elements which make the customer perceived value and the relations to customer satisfaction (measured through Recruitment rate) and loyalty. Moreover, from the graph it turns out that the demand of product-services is generated by the repeated business of loyal customers together with the assist requests coming from new customers.

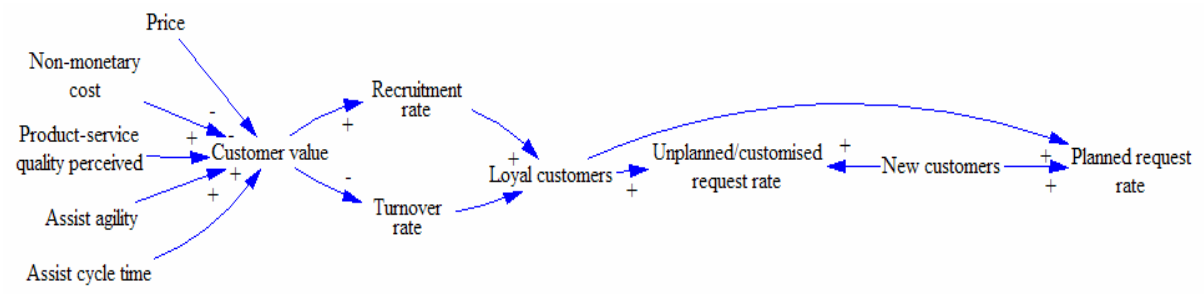

Fig. 1. The customer perspective

\subsection{The Service Network Perspective}

The service network perspective is related to operational results that the service network can achieve through its ability in satisfying both planned and unplanned/customised pending requests. This area depicts the relations existing among:

- reliability (RL), measured by the combinations of perfect assist completion of planned and unplanned/customised requests;

- responsiveness (RS), measured through the assist cycle time;

- agility (AG), measured through assist agility.

The performance and operational outcomes strongly depend on the interrelations among all the actors of the service network and on the effectiveness of their coordination. Some interesting contributions that helped to build the loop can be found in [6], [4] and [16]. The main relations are shown in Figure 2.
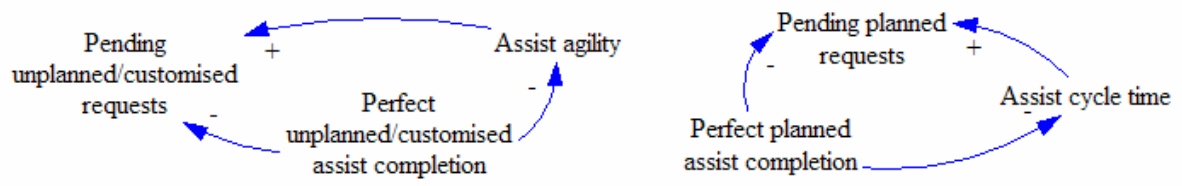

Fig. 2. The service network perspective 


\subsection{The Company Perspective}

The company perspective is more related to the financial performance results which justify the costs and investments carried out on the AS unit. It aims at identifying the relations among:

- costs (CO), measured through the assist-warranty-spare parts costs;

- growth (GR), measured in terms of assist operating income;

- asset management (AM) investment strategies, measured in terms of return on assist assets.

This diagram starts with the generation of AS revenue, that is the key to profitability and company growth [7]. According to [15], it is important that a company understands the way a service system can be improved over time through investments in order to achieve high efficiency, effectiveness and sustainability. Literature contributions that have been analysed to build this loop are [2] and [17]. The main relations are shown in Figure 3.

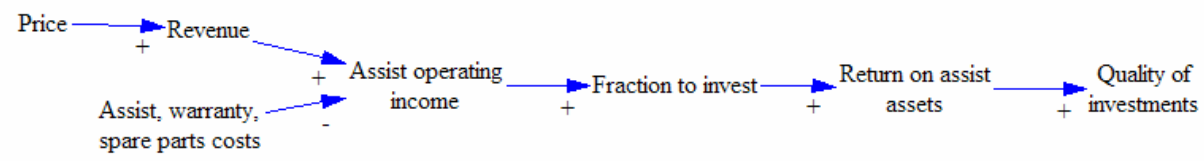

Fig. 3. The company perspective

\section{The Developed Model}

From the analysis reported in $\S 3$, it comes out that the main scientific works describe locally or partially the AS service system elements and relations. According to the three main identified actors, the customer perspective can count on numerous contributions since this is a topic widely covered and argued by the marketing literature. Few works dealing with the operations management field, instead, have been found covering the company and the service network perspectives: this may be due to the fact that AS is still a relatively new topic not yet completely exploited. Examples of complete service or AS service system modelling are also quite scant. The model displayed in Figure 4 aims at describing the whole AS system and at capturing the interactions among the KPIs reported in Table 1. It has been conceived according to a Systems Thinking logic and is based on the following hypothesis:

- it represents the behaviour of the AS service system as an independent business unit which strongly interacts with a downstream service network;

- it refers to services supporting the product (Product-Services), where the service focus is on basic services such as documentation, installation, help desk, repairs, upgrades, reconstruction and recycling.

The model highlights the interlinked relations which make up the AS system and how the three perspectives are related each other. Referring to the dotted lines in Figure 4, starting from the customer perspective, the perceived Customer value is derived from 
some non-monetary costs, the perceived quality of product-services, the service network operational results - in terms of responsiveness (Assist cycle time), flexibility (Assist agility) and indirectly reliability (Perfect planned and unplanned/customised assist completion) - and the price set up by the company. Moreover, the customer purchasing requests of loyal customers (measured in terms of Planned and Unplanned/customised request rate) have an impact both on the service network, which needs to be organised to satisfy the demand (Pending planned and unplanned/customised requests), and the company costs (Assist, warranty, spare parts costs). Regarding the company perspective, as just mentioned, operational costs depend on the number of customer requests (Planned and unplanned/customised requests); revenues are influenced by the number of reliable assistance interventions performed by the service network (Perfect planned and unplanned/customised assist completion). The company, furthermore, if it is profitable, can make strategic investments to improve its tangible and intangible assets (Quality of investments) and consequently the relations with its service network.

In conclusion, as also Figure 4 shows, AS system and its dynamics cannot be depicted through a linear representation: there are lots of interlinked relations and feedback loops that need to be considered and explored.

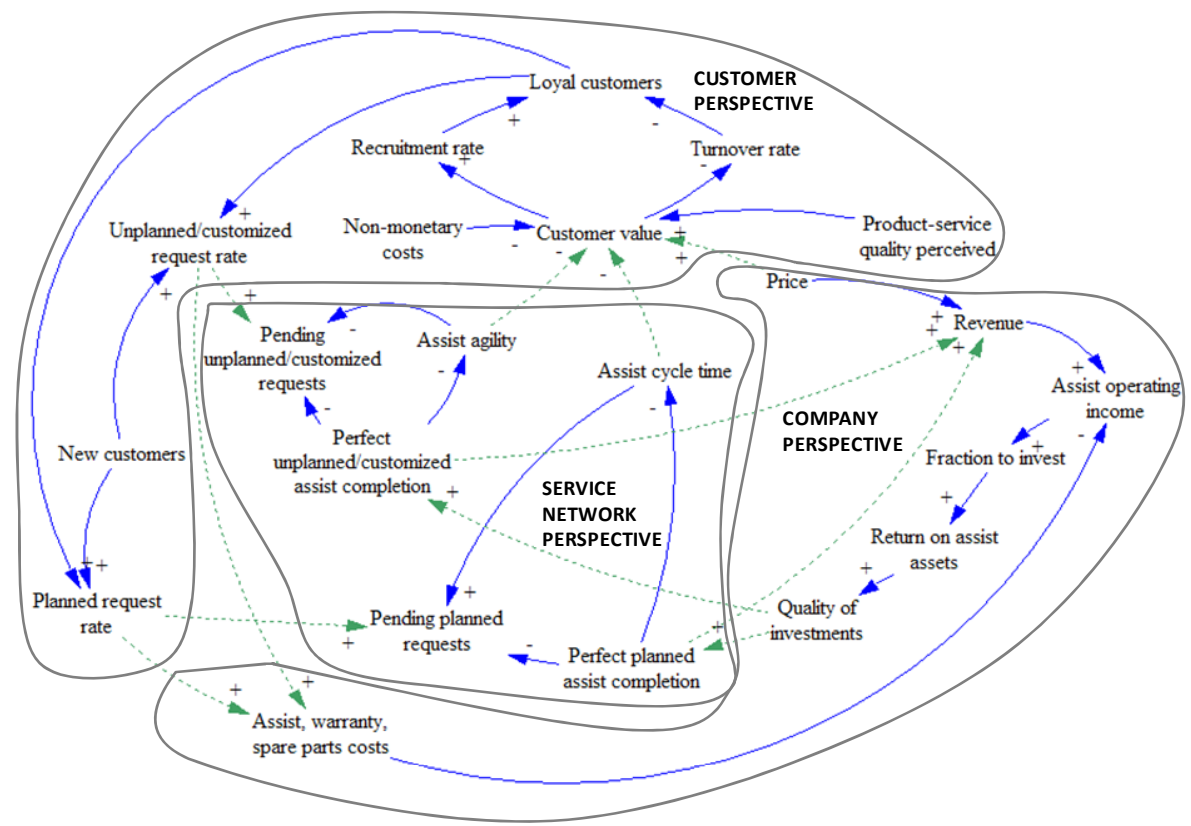

Fig. 4. Relationships within the AS service system and its performance results

\section{Conclusions and Further Developments}

Although in the past and present years a considerable amount of literature has dealt with the topic of service modelling, most of these contributions are about descriptive 
models which depict scenarios in a static and linear form without any evaluation analysis of the underneath dynamics. In this paper, the causal-loop relationships existing among AS performance KPIs and their connections with the three main identified actors, have been explored and supported by a literature analysis. The proposed model has been carried out through a Systems Thinking approach in order to identify the key logic relations; it is based on some assumptions and actually it is strongly theoretically based. Further work will imply a more massive use of System Dynamics methodology and, in particular, it will regard the identification of causal diagrams showing stock and flow structures, the definition of mathematical and logic equations, simulation runnings and what-if analyses. To make a quantitative examination, data will be collected through a survey conducted within the ASAP Service Management Forum network (http://www.asapsmf.org/), an Italian forum finalized to the promotion of cultural and scientific activities in the AS area, with specific know-how in the automotive, domestic appliances, machinery and digital systems industries. Final goal will be to identify the main prior relations among the KPIs for some specific industries and, consequently, find out the beneath related AS processes to enhance.

\section{References}

1. Angerhofer, B.J., Angelides, M.C.: System dynamics modelling in supply chain management: research review. In: Proc. of the 2000 Winter Simulation Conference, pp. 342-351 (2000)

2. Camerinelli, E., Cantu, A.: Linking supply chain measures with financial performance: a framework.Technical Report, Supply Chain Council Research (2006)

3. Crespo, M.A., Blanchar, C.: A decision support system for evaluating operations investments in high-technology business. Decision Support Systems 41, 472-487 (2006)

4. Gaiardelli, P., Saccani, N., Songini, L.: Performance measurement systems in the aftersales service: an integrated framework. International Journal Business Performance Management 9(2), 145-171 (2007)

5. Heskjett, J., Jones, T., Loveman, G., Sasser, W., Schlesinger, L.: Putting the service-profit chain at work. Harvard Business Review (March-April 1994)

6. InCoCo's 2007, EU-funded project (2007), http: / / www . incoco . net/

7. Kingman-Brundage, J., George, W.R., Bowen, D.E.: "Service logic": achieving service system integration. International Journal of Service Industry Management 6(4), 20 (1995)

8. Legnani, E., Cavalieri, S.: Measuring the performance of after-sales service processes. A hierarchical approach. In: Proc. of APMS 2008, International Conference on Innovations in network, Espoo, Finland, pp. 359-368 (2008)

9. Oliva, R., Kallenberg, R.: Managing the transition from products to services. International Journal of Service Industry Management 14(2), 160-172 (2003)

10. Potts, G.W.: Exploiting your product's service life cycle. Harvard Business Review 66(5), 32-35 (1988)

11. Rust, R.T., Metters, R.: Mathematical models of service. European Journal of Operational Research 91, 427-439 (1996)

12. Santos, S.P., Belton, V., Howick, S.: Adding value to performance measurement by using system dynamics and multicriteria analysis. International Journal of Operations \& Production Management 22(11), 1246-1272 (2002)

13. Sawhney, M., Balasubramanian, S., Krishnan, V.V.: Creating growth with services. MIT Sloan Management Review (2004) 
14. Schneider, B., Bowen, D.E.: Winning the service game. Harvard Business School Press, Boston (1995)

15. Spohrer, J., Maglio, P.P., Bailey, J., Gruhl, D.: Steps toward a science of service systems. Computer 40(1), 71-77 (2007)

16. Sterman, J.: Business dynamics: system thinking and modelling for a complex world. McGraw-Hill, New York (2000)

17. Supply Chain Council (SCC): Supply Chain Operations Reference model (SCOR), version 9.0 (2008), http: / / www . supply-chain.org

18. Wise, R., Baumgartner, P.: Go downstream - the new profit imperative in manufacturing. Harvard Business Review 77, 133-141 (1999)

19. Zeithaml, V.A., Parasuraman, A., Berry, L.L.: Delivering quality service: balancing customer perceptions and expectations. Free Press, New York (1990) 